\title{
Delivery of a transforming growth factor $\beta$-I plasmid to mesenchymal stem cells via cationized Pleurotus eryngii polysaccharide nanoparticles
}

This article was published in the following Dove Press journal:

polysaccharide nanoparticles

13 March 2012

Number of times this article has been viewed

\author{
Wen Wen Deng* \\ Xia Cao* \\ Miao Wang* \\ Rui Qu \\ Wei Yan Su \\ Yan Yang \\ Ya Wei Wei \\ Xi Ming $X u$ \\ Jiang $\mathrm{Nan} \mathrm{Yu}$
}

Department of Pharmaceutics, School of Pharmacy and Center for Nano Drug/Gene Delivery and Tissue Engineering, Jiangsu University, Zhenjiang, People's Republic of China

*These authors contributed equally to this work
Correspondence: Xi Ming Xu; Jiang Nan Yu

Department of Pharmaceutics,

School of Pharmacy, Jiangsu University,

30I Xuefu Road, Jingkou District,

Zhenjiang 21200I, People's Republic

of China

Tel $+865118503845 I$

Fax +86 5118503845 I

Email xmxu@ujs.edu.cn; yjn@ujs.edu.cn
Abstract: The objective of this study was to investigate the use of cationized Pleurotus eryngii polysaccharide (CPEPS) as a nonviral gene delivery vehicle to transfer plasmid DNA encoding transforming growth factor beta-1 (pTGF- $\beta 1$ ) into mesenchymal stem cells (MSCs) in vitro. Crude $P$. eryngii polysaccharide was purified, and then cationized by grafting spermine onto the backbone of the polysaccharide. Agarose gel electrophoresis, transmission electron microscopy, and a Nano Sense Zetasizer (Malvern Instruments, Malvern, UK) were used to characterize the CPEPS-pTGF- $\beta 1$ nanoparticles. The findings of cytotoxicity analysis showed that when the nanoparticles were formulated with a CPEPS/pTGF- $\beta 1$ weight ratio $\geq 10: 1$, a greater gel retardation effect was observed during agarose gel electrophoresis. The CPEPS-pTGF- $\beta 1$ nanoparticles with a weight ratio of 20:1, respectively, possessed an average particle size of $80.8 \mathrm{~nm}$ in diameter and a zeta potential of $+17.4 \pm 0.1 \mathrm{mV}$. Significantly, these CPEPS-pTGF- $\beta 1$ nanoparticles showed lower cytotoxicity and higher transfection efficiency than both polyethylenimine $(25 \mathrm{kDa})(P=0.006$, Student's $t$-test $)$ and Lipofectamine ${ }^{\mathrm{TM}} 2000$ ( $P=0.002$, Student's $t$-test). Additionally, the messenger RNA expression level of TGF- $\beta 1$ in MSCs transfected with CPEPS-pTGF- $\beta 1$ nanoparticles was significantly higher than that of free plasmid DNA-transfected MSCs and slightly elevated compared with that of Lipofectamine 2000-transfected MSCs. Flow cytometry analysis demonstrated that $92.38 \%$ of MSCs were arrested in the G1 phase after being transfected with CPEPS-pTGF- $\beta 1$ nanoparticles, indicating a tendency toward differentiation. In summary, the findings of this study suggest that the CPEPS-pTGF- $\beta 1$ nanoparticles prepared in this work exhibited excellent transfection efficiency and low toxicity. Therefore, they could be developed into a promising nonviral vector for gene delivery in vitro.

Keywords: nonviral gene vector, transfection, plasmid DNA, spermine

\section{Introduction}

Gene therapy has been well defined as a strategy for transferring nucleic acids, such as therapeutic DNA, antisense oligonucleotides, and small interfering RNA, to the target tissues or cells to correct or supplement the defective genes that are responsible for disease development. ${ }^{1-4}$ The ideal gene delivery system must be able to protect the nucleic acid from many types of degrading systems such as DNA-degrading enzymes and lysosomes, ${ }^{5}$ in order to penetrate the cell membrane and gain entry into the target cells, and to promote efficient gene expression. The system must also possess specific properties including biocompatibility, biodegradability, nontoxicity, nonimmunogenicity, and stability, during storage and treatment. ${ }^{1,6}$ However, the lack of safe and efficient vectors for DNA delivery is currently a major hurdle for the success of gene therapy. 
Gene delivery systems can be classified into viral and nonviral systems. ${ }^{7}$ Despite the fact that viral gene carriers are widely employed in clinical treatments due to their high transfection efficiency and long-term gene expression, ${ }^{8,9}$ there are several limitations that impede their applications, including immunogenic properties and the potential to cause mutational infection and toxic side effects. ${ }^{10}$ Nonviral gene vectors have emerged as a promising alternative to viral vectors because they offer such advantages as low immunogenicity, increased biological safety, the ability to deliver large genes, excellent flexibility in their building block structures, and the possibility of large-scale production at a reasonable cost. ${ }^{11,12}$

As the leading nonviral gene vectors, cationic polymers can form complexes with the negatively charged nucleic acids so that large pieces of these nucleic acids can be condensed to nanometer-sized particles. This promotes the interaction of cationic polymers with the negatively charged cell membrane, which protects the incorporated nucleic acids in the complex from many types of degrading systems. ${ }^{13,14}$ A large number of cationic polymers have been designed as gene carriers, such as cationized gelatin, ${ }^{15}$ poly(L-lysine) (PLL) polymers, ${ }^{16-18}$ polyethylenimine (PEI),${ }^{19-21}$ and so on. However, these polymers suffer several inherent disadvantages including high toxicity, poor biodegradability, and low transfection efficiency.

In recent years, cationic polysaccharide, a type of natural, water-soluble, nontoxic, biocompatible and biodegradable cationic polymer, has been receiving increasing scientific attention and is considered to be the most attractive candidate for gene transfer. ${ }^{22}$ Compared with other cationic polymers, cationic polysaccharide presents such advantages as the presence of groups that can be easily modified to improve the physicochemical properties and cellular uptake, which can be facilitated by a sugar-recognition receptor on the cell surface..$^{23}$ Chitosan, a naturally occurring linear amino polysaccharide, has been reported as a vector for gene delivery. ${ }^{24}$ Researchers have found that apart from its biocompatibility, biodegradability, and low toxicity, chitosan and its derivatives showed excellent ability to transfer genes into cells. ${ }^{25-27}$ However, chitosan has demonstrated lower transfection efficiency compared with conventional nonviral gene carriers such as liposomes, ${ }^{28} \mathrm{PEI},{ }^{29}$ and Lipofectamine ${ }^{\mathrm{TM}} 2000$ (Invitrogen, Carlsbad, CA).${ }^{30}$ Other leading cationic polysaccharides that have been investigated as gene vectors include dextran, ${ }^{7,31-33}$ pullulan, ${ }^{34,35}$ pectin, ${ }^{36}$ and schizophyllan. ${ }^{22,37}$

The cationization of polysaccharide is a promising strategy to develop nonviral gene vectors for use in gene therapy. ${ }^{38,39}$ Polysaccharides represent a structurally diverse class of macromolecules of widespread occurrence in nature and offer a high capacity for carrying biological information because they have great potential for structural variability. ${ }^{40}$ In support of the above findings, the aim of this study was to develop a nonviral gene vector by grafting spermine residues onto a polysaccharide extracted from Pleurotus eryngii. P. eryngii is an edible mushroom which is very common in China. Mushrooms are known for their nutritional and medicinal values as well as for the diversity of their bioactive components such as nucleases ${ }^{41}$ proteases, ${ }^{42}$ and polysaccharides. ${ }^{43,44}$ They also contain polysaccharide-peptide and polysaccharide-protein complexes. ${ }^{45}$ So far, most of the research regarding $P$. eryngii has focused on its enzymes. ${ }^{46-48}$ One of the major components of $P$. eryngii, the polysaccharide of $P$. eryngii (PEPS), has been studied because of its positive health effects, which include cholesterol-lowering, antioxidant, and anticancer activities; however, little investigation into its application as a gene vector has been carried out. ${ }^{49}$ Previous studies have indicated that the polysaccharides isolated from P. eryngii were mostly $\beta$-glucans, which exhibited potential prebiotic activities. ${ }^{50}$ Therefore, to construct a cationic polysaccharide for use as a gene carrier, this study chemically modified PEPS by the reductive amination method. Cationized PEPS (CPEPS) enjoys the merits of both the positive charge of amine compounds and the bioactivity of PEPS. This advantage is favorable for delivering plasmid DNA into cells in vitro.

Nanoparticles are a desirable vehicle for gene delivery because of their nanoscale particle size, good stability, and excellent diffusion properties, which may facilitate cellular uptake..$^{51,52}$ The plasmid encoding transforming growth factor beta-1 (TGF- $\beta 1$ ) was used in the study. TGF- $\beta 1$ is a widely used cytokine which can participate in and regulate many kinds of biochemical processes, including cell growth and differentiation, the formation of extracellular matrices, cytoadherence, immunoregulation, embryonic development, and wound healing. ${ }^{53,54}$ It has been reported that TGF- $\beta 1$ was able to induce mesenchymal stem cells (MSCs) to differentiate into chondrocytes in three-dimensional scaffolds, and this study is exactly aimed at this direction. Therefore, plasmid TGF- $\beta 1$ (pTGF- $\beta 1$ )was combined with CPEPS, resulting in CPEPS-p TGF- $\beta 1$ nanoparticles that would have the ability to condense large plasmid DNA into nanoscaled supermolecular assemblies. The driving force for the complexation comes from the attraction between the two oppositely charged ions of each polyelectrolyte. Such properties as particle size distribution, zeta potential, and gel retardation 
effect were rigorously tested to characterize the CPEPS. Most importantly, the in vitro transfection efficiency of the CPEPS/plasmid DNA nanoparticles was investigated, and cytotoxicity was also tested by the 3-(4,5-dimethylthiazol2-yl)-2,5-diphenyltetrazolium bromide (MTT) method. ${ }^{55}$ It is expected that CPEPS could be developed into a promising nonviral gene vector for gene therapy.

\section{Materials and methods Materials}

P. eryngii were kindly provided by the Zhenjiang edible mushroom growth base (Zhenjiang, China). Spermine and branched PEI (molecular weight $25 \mathrm{kDa}$ ) were purchased from Sigma-Aldrich (St Louis, MO). Dulbecco's modified Eagle's medium (DMEM), penicillin-streptomycin, trypsin, MTT, fetal bovine serum (FBS), and Lipofectamine 2000 were obtained from Invitrogen (Carlsbad, CA). All other chemicals and reagents were of analytical or even higher grade and were used without further purification. All solutions were prepared with double distilled water (DDW). The experimental protocol was approved by the University Ethics Committee for the use of experimental animals and conformed to the Guide for the Care and Use of Laboratory Animals. ${ }^{56}$

\section{Polysaccharide extraction and purification}

The polysaccharide was extracted from the fruiting bodies of P. eryngii by purification, as illustrated in Figure 1. The milled fruiting bodies of P. eryngii (2000 g) were extracted with $2 \mathrm{~L}$ of distilled water at $90^{\circ} \mathrm{C}$ for 3 hours (repeated three times). The aqueous extracts were concentrated under reduced pressure at $50^{\circ} \mathrm{C}$ and precipitated with absolute ethanol (with a final ethanol concentration of $75 \%(\mathrm{v} / \mathrm{v}))$. The precipitate was washed twice with absolute ethyl alcohol, and further dissolved in distilled water. This was dialyzed for 48 hours against distilled water (molecular weight cutoff [MWCO] 8000-14,400, Biosharp). ${ }^{39}$ The retentate portion was centrifuged to remove insoluble material. The supernatant was lyophilized, and then primrose-yellow crude PEPS was obtained.

The crude PEPS was purified by anion-exchange chromatography on a column $(D 2.6 \mathrm{~cm} \times 40 \mathrm{~cm}$, Shanghai Huxi Analysis Instrument Factory Co, Ltd, China) filled with DEAE-52 cellulose resin (Whatman, UK). Then, the fractions that were collected from the DEAE-52 cellulose resin chromatographic column were loaded onto the SephadexG-100 (Shanghai Richu Bioscience Co, Ltd, China) gel chromatographic column $(D 2.6 \mathrm{~cm} \times 40 \mathrm{~cm}$, Shanghai Huxi Analysis Instrument Factory). Fractions were collected and monitored

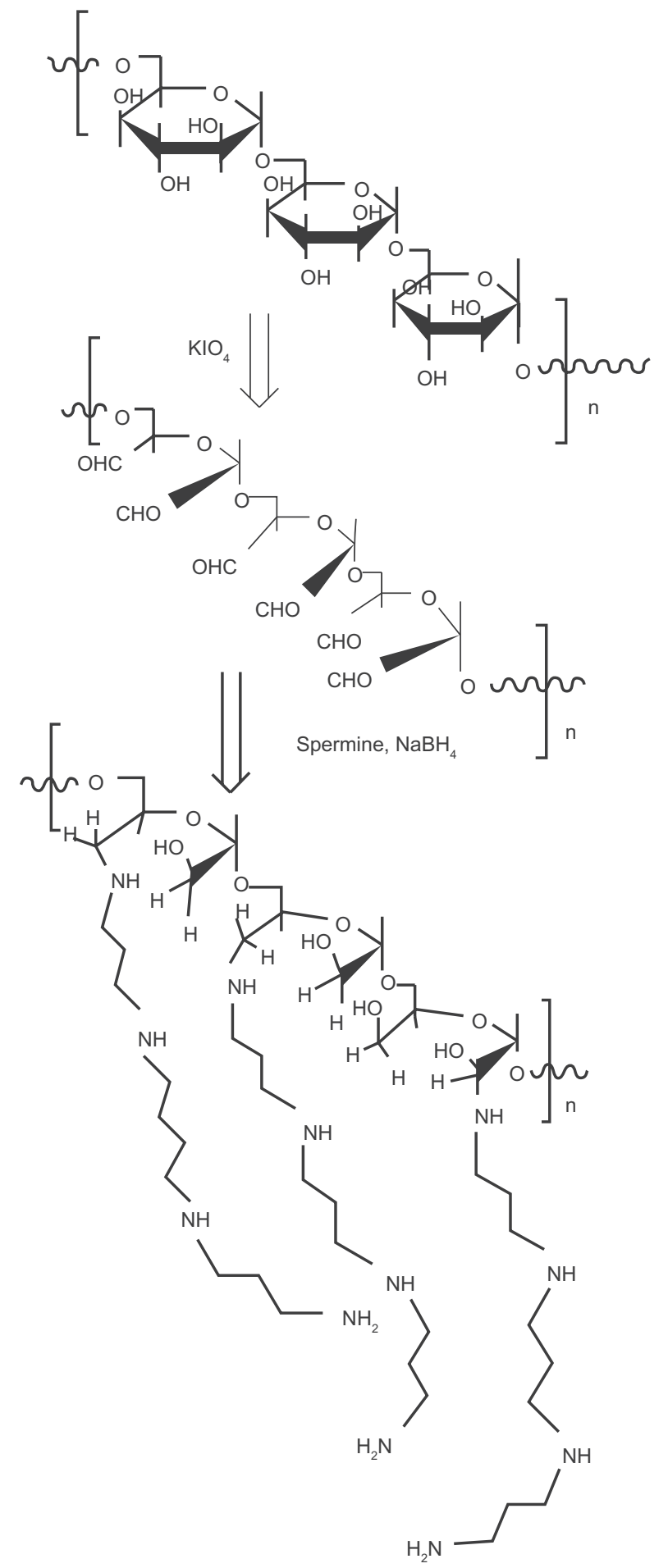

Figure I The process of polysaccharide of Pleurotus eryngii extraction and purification.

for the presence of carbohydrate with a phenol-sulfuric acid assay. ${ }^{57}$ A single peak was observed with an ultraviolet (UV) absorption photometry instrument (UV2401PC, Shimadzu, Tokyo, Japan). The target fractions were combined and dialyzed against distilled water (MWCO 3500, Biosharp). ${ }^{39}$ After lyophilization, purified PEPS was obtained. 


\section{Preparation of CPEPS}

The CPEPS was prepared by the reductive amination method (Figure 2) according to a previous study, ${ }^{32}$ with slight modifications. The process is shown in Figure 3. The PEPS ( $0.5 \mathrm{~g}, 3.125 \mathrm{mmol}$ of glucose units) was dissolved in $50 \mathrm{~mL}$ of DDW which was followed by the addition of potassium periodate $\left(0.716 \mathrm{~g}\right.$, with an $\mathrm{IO}_{4}^{-} /$saccharide molar ratio of $\left.1: 1\right)$. The mixture was quickly placed in a darkroom to allow it to react at room temperature with vigorous magnetic stirring for 72 hours. The resulting polyaldehyde derivative was dialyzed (MWCO 3500, Biosharp) $)^{39}$ for another 48 hours against DDW. After freeze-drying, oxidized PEPS was obtained.

The aldehyde content was determined according to Jun-ichiro et al. ${ }^{58}$ Oxidized PEPS (0.3 g) was dissolved in $20 \mathrm{~mL}$ of freshly prepared hydroxylamine hydrochloride water solution $(0.25 \mathrm{M}, \mathrm{pH} 4)$. The resulting mixture was then gently stirred overnight at room temperature, followed by titration with standardized sodium hydroxide solution $(0.1 \mathrm{M})$ till the end point as recorded on a digital pH meter (model PHS-3TC, Shanghai Tainda, Shanghai, China) was reached.

A solution of oxidized PEPS (containing $6.77 \mathrm{mmol}$ of aldehyde groups) in $50 \mathrm{~mL}$ of DDW was slowly added (using a Sage Metering pump model 365 [Sage Metering,

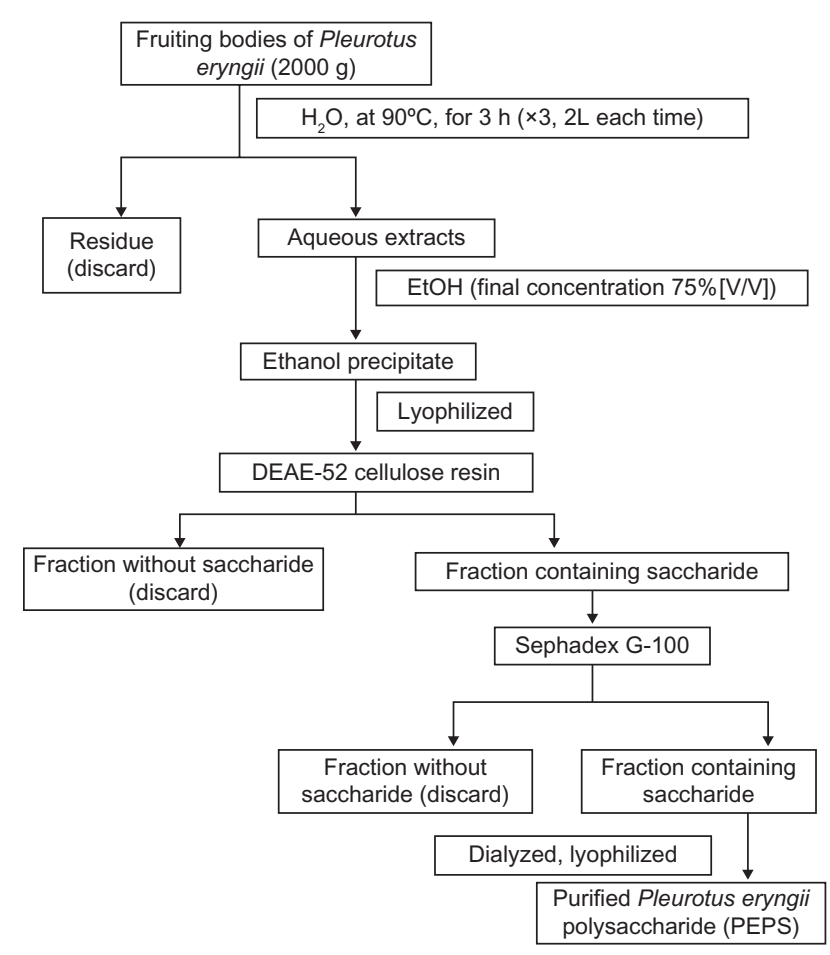

Figure $\mathbf{2}$ The process of spermine grafting to the polysaccharide (dextran is used as an example).

Notes: The reductive amination method is used to produce the cationized polysaccharide: the polysaccharide is first oxidized by $\mathrm{KIO}_{4}$; after the addition of spermine, $\mathrm{NaBH}_{4}$ is used to reduce the reactants.
Monterey, CA]) over 2 hours to a basic solution containing a 1.25 equimolar amount of spermine $(8.46 \mathrm{mmol})$ dissolved in $30 \mathrm{~mL}$ of borate buffer $(0.1 \mathrm{M}, \mathrm{pH} 11)$. The mixture was then gently stirred at room temperature for 24 hours. Then, $\mathrm{NaBH}_{4}$ $(0.3 \mathrm{~g})$ was added to the mixture to react for 48 hours and the process was repeated with an additional portion of $\mathrm{NaBH}_{4}$ $(0.3 \mathrm{~g})$ for another 24 hours under the same conditions. The resulting light-yellow solution was dialyzed (MWCO 3500, Biosharp) for 48 hours against DDW. After freeze-drying, cationized PEPS (CPEPS) was obtained.

\section{Characterization of PEPS and CPEPS}

Based on the literature and the limited experimental conditions in our laboratory, in this study, the average molecular weights of PEPS and CPEPS were analyzed with a Shimadzu gel permeation chromatography (GPC) system-equipped Shimadzu RID-10A refractive index detector (RID) (LC-10 AVP, Shimadzu). Analysis of the monosaccharide composition of PEPS was preliminarily determined by thin layer chromatography. After the spermine modification, the quantity of spermine residues that were grafted onto the PEPS was reflected by the amount of primary amino groups determined by the trinitrobenzene sulfonic acid

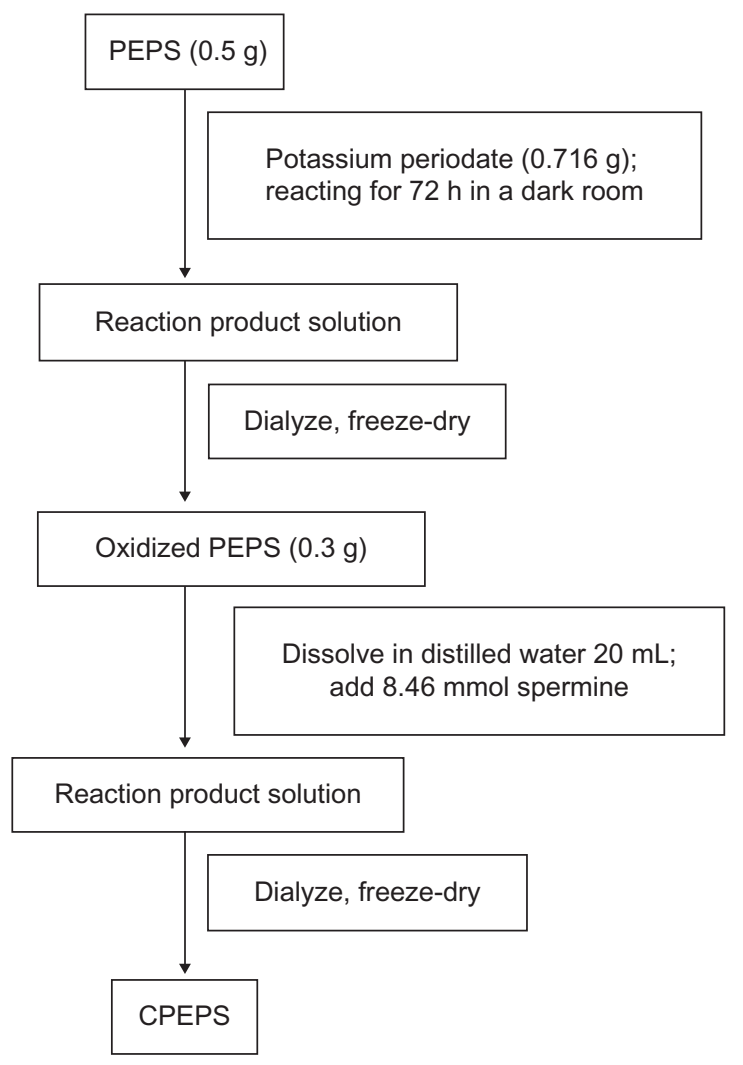

Figure 3 The process of cationized Pleurotus eryngii polysaccharide (CPEPS) preparation. 
method. The quantity of total nitrogen per unit weight of polymer was determined with a Euro EA elemental analyzer. A Fourier transform infrared spectrometer $(\mathrm{KBr})$ (Nicolet 170SX, Thermo Fisher Scientific, Waltham, MA) was used to characterize the PEPS and CPEPS and to retrieve their structural information.

\section{Preparation of plasmid DNA}

The TGF- $\beta 1$ was amplified in Escherichia coli host strain $\mathrm{DH} 5 \alpha$ and purified by column chromatography with the PureYield ${ }^{\text {TM }}$ Plasmid Maxiprep Start-Up Kit (Promega, Madison, WI) according to the manufacturer's protocol. Ampicilin was used to select for the pTGF- $\beta 1$-transformed cells. The DNA concentration was quantified by measuring the UV absorbance at $260 \mathrm{~nm}$ with a UV spectrophotometer (DU 530 Life Science UV/Vis spectrophotometer; Beckman Coulter, Fullerton, CA).

\section{Preparation of CPEPS-pTGF- $\beta$ I nanoparticles}

The CPEPS-pTGF- $\beta 1$ nanoparticles were prepared by complex coacervation. A number of CPEPS-pTGF- $\beta 1$ nanoparticle samples that differed in their CPEPS/pTGF- $\beta 1$ weight ratios were prepared. The CPEPS stock solution ( $8 \mathrm{mg} / \mathrm{mL}$ ) was made by dissolving $8 \mathrm{mg}$ CPEPS in $1 \mathrm{~mL}$ distilled water, which was then sterilized by heating at $80^{\circ} \mathrm{C}$ for 4 hours. The required solutions for the different CPEPS concentrations and that of the pTGF- $\beta 1$ concentration $(400 \mu \mathrm{g} / \mathrm{mL})$ were prepared with sterilized DDW. Meanwhile, aliquots $(100 \mu \mathrm{L})$ of each of the CPEPS and pTGF- $\beta 1$ working solutions were heated separately at $55^{\circ} \mathrm{C}$ for 30-45 minutes. Equal volumes of each solution were then quickly mixed and vortexed for 60 seconds to obtain the CPEPS-pTGF- $\beta 1$ nanoparticles.

\section{Analysis of gel retardation effect of CPEPS-pTGF- $\beta$ I nanoparticles}

The CPEPS-pTGF- $\beta 1$ retention effect was analyzed using gel electrophoresis. CPEPS-pTGF- $\beta 1$ nanoparticle solutions $(10 \mu \mathrm{L})$ with different weight ratios were mixed with $1 \mu \mathrm{L}$ loading buffer $(0.1 \%$ sodium dodecyl sulfate, $5 \%$ glycerol, and $0.005 \%$ bromophenol blue) and put into $1 \%$ agarose gel in tris-borate-ethylenediaminetetraacetic acid buffer solution ( $\mathrm{pH} 8.0$ ) containing $1 \mu \mathrm{g} / \mathrm{mL}$ ethidium bromide. The diluted free pTGF- $\beta 1$ solution $(10 \mu \mathrm{L})$ was used as a control. Electrophoretic evaluation of the complex was carried out in tris-borate-ethylenediaminetetraacetic acid buffer solution at $80 \mathrm{~V}$ for 90 minutes. A photograph of the gel was taken with a UV transilluminator (Gel Doc 2000, Bio-Rad, Hercules, CA).

\section{Zeta potential}

The zeta potentials of the nanoparticle suspensions, which had different weight ratios of CPEPS to pTGF- $\beta 1$ (10:1, 20:1, and 30:1), were measured with a ZEN3600 Nano Series Zetasizer (Malvern Instruments, Malvern, UK). The zeta potentials of the free plasmid and original CPEPS were determined under the same conditions. This measurement would reflect the degree of cationization.

\section{Determination of the nanoparticle size distribution}

The nanoparticle size distribution was determined by a dynamic light scattering (DLS) technique, performed at $25^{\circ} \mathrm{C}$ with a Brookhaven BI-90plus instrument (Brookhaven Instruments Corporation, Holtsville, NY). The measured scattering intensities were then analyzed by the software provided by Brookhaven. The determination limits of the size distribution generally ranged from $1 \mathrm{~nm}$ to $6 \mu \mathrm{m}$, with high sensitivity and reproducibility.

\section{Transmission electron microscopy (TEM)}

TEM (JEM-2100; JEOL, Tokyo, Japan) was used to detect the size and shape of the nanoparticles. Samples were prepared by placing $1 \mu \mathrm{L}$ nanoparticle suspension onto a copper screen and allowing them to air-dry. Then, the air-dried samples were observed directly under TEM without the need to coat the samples with a conducting layer as is required for conventional scanning electron microscopy.

\section{Isolation and culture of MSCs}

The method of isolation and culture of MSCs was as described by Alhadlaq and Mao. ${ }^{59}$ The MSCs were isolated from 1-month-old rats by flushing the femurs and tibias with phosphate-buffered solution (PBS, pH 7.4). This was followed by the collection of $5 \mathrm{~mL}$ bone marrow suspensions into centrifuge tubes. Lymphocyte cell separation buffer $(5 \mathrm{~mL})$ was gently added into each tube along the walls of the tube. After centrifugation, a mist-like layer containing most of the MSCs had formed. The mist-like layer was then carefully collected into new tubes and washed twice with PBS. After centrifugation, the precipitate was suspended in cell culture medium containing DMEM, 10\% FBS, low glucose (1\%), $100 \mathrm{U} / \mathrm{mL}$ penicillin, and $100 \mu \mathrm{g} / \mathrm{mL}$ streptomycin. The resulting suspension was transferred into cell culture flasks. The cells were incubated at $37^{\circ} \mathrm{C}$ in a humidified atmosphere of $5 \% \mathrm{CO}_{2}$. 


\section{Cytotoxicity assay}

The in vitro cytotoxicity of the different CPEPS-pTGF- $\beta 1$ nanoparticles (weight ratios 10:1; 20:1; 30:1) was examined by MTT dye reduction assay. The second-passage MSCs were seeded in a 96-well plate at a cell density of $2.5 \times 10^{4}$ cells/well and incubated at $37^{\circ} \mathrm{C}$ for 24 hours in $100 \mu \mathrm{L}$ of DMEM containing $10 \%$ FBS. After that, the medium was removed and replaced with a $100 \mu \mathrm{L}$ suspension of CPEPS-pTGF- $\beta 1$ nanoparticles (pTGF- $\beta 1200 \mathrm{ng} /$ well) which had been diluted in a serum-free medium. Lipofectamine 2000/pTGF- $\beta 1$ and branched PEI ( $25 \mathrm{kDa}) / \mathrm{pTGF}-\beta 1$ were employed as control groups according to each manufacturer's protocol, under the same conditions. This was to ensure that the optimal ratios for transfection were used. The concentration of pTGF- $\beta 1$ in each group was $2 \mathrm{ng} / \mu \mathrm{L}$. The same concentration of pTGF- $\beta 1$ was used in the subsequent experiments.

Cell viability was tested after the addition of the CPEPSpTGF- $\beta 1$ complexes for 48 hours at $37^{\circ} \mathrm{C}$ in $5 \% \mathrm{CO}_{2}$. After that, $10 \mu \mathrm{L}$ of MTT solution $(5 \mathrm{mg} / \mathrm{mL})$ was added to each well for an additional 4-hour incubation under the same conditions. The MTT-containing medium was then removed, and $100 \mu \mathrm{L}$ dimethyl sulfoxide was added. Dimethyl sulfoxide was used to dissolve the formazan crystals that were formed by the living cells. The absorbance was measured at $570 \mathrm{~nm}$ using a microplate reader (SpectraMax 190; Molecular Devices, Sunnyvale, CA). The measured absorbance was normalized with the absorbance of nontreated control cells.

\section{In vitro transfection experiments}

In the transfection experiment, second-passage MSCs were seeded in 96-well plates at a density of $2.5 \times 10^{4}$ cells/well in $100 \mu \mathrm{L}$ complete culture medium (DMEM, containing $10 \%$ FBS) and incubated for a period of 24 to 48 hours to obtain a confluence of $80 \%$ before transfection. The medium was then removed and replaced with a $100 \mu \mathrm{L}$ suspension of CPEPS-pTGF- $\beta 1$ nanoparticles (pTGF- $\beta 1200 \mathrm{ng} /$ well) in a serum-free medium, which contained DMEM, $100 \mathrm{U} / \mathrm{mL}$, and $100 \mu \mathrm{g} / \mathrm{mL}$ streptomycin glutamate. In the positive control groups, Lipofectamine 2000/pTGF- $\beta 1$ and branched PEI $(25 \mathrm{kDa}) / \mathrm{pTGF}-\beta 1$ were handled rigorously according to the protocols provided by the manufacturers and naked pTGF- $\beta 1$ ( $200 \mathrm{ng} /$ well) in serum-free medium was used for the negative control group. Four hours later, the medium was replaced with $100 \mu \mathrm{L}$ fresh complete medium and the cells were incubated for 72 hours. A rat TGF- $\beta 1$ enzyme-linked immunosorbent assay kit (Yantai Addcare Biotech, Shandong, China) was used to detect cell transfection efficiency, according to the protocol.

\section{RNA isolation and reverse transcriptase polymerase chain reaction}

Similar to the enzyme-linked immunosorbent assay test, second-passage MSCs were seeded in six-well plastic culture plates at a density of $2 \times 10^{6}$ cells/well in $2 \mathrm{~mL}$ complete culture medium (DMEM, containing 10\% FBS) and incubated for $24-48$ hours to obtain a confluence of $80 \%$. This was followed by transfection as described above. After 24 hours of transfection, total RNA was extracted using TRIzol ${ }^{\circledR}$ Reagent (Invitrogen), thus following the instructions provided by the manufacturer. RNA concentration and purity were measured by a spectrophotometer (NanoDrop Technologies, Wilmington, DE).

Reverse transcriptase polymerase chain reaction analysis was carried out to determine the messenger RNA (mRNA) expression level of TGF- $\beta 1$. The reverse transcriptase reaction was conducted with 1.0 ug total RNA using a RevertAid ${ }^{\mathrm{TM}}$ cDNA First Strand Synthesis Kit (K1622; Thermo Fisher Scientific, Shenzhen, China). The following polymerase chain reaction (PCR) amplification reaction utilized the Taq polymerase and specific primers. The specific sequences of the primers for PCR were 5'-TGGTGGACCGCAACAACGCA-3' (forward primer) and 5'-TGCACGGGACAGCAATGGGG-3' (reverse primer) (GenBank Accession No NM 021578.2). In this study, glyceraldehyde 3-phosphate dehydrogenase was used as an internal standard. The PCR was run in an iCycler (Bio-Rad) using a Brilliant II SYBR ${ }^{\circledR}$ Green QPCR Master Mix (Stratagene, La Jolla, CA). The PCR conditions were as follows: $95^{\circ} \mathrm{C}$ for 10 minutes (for initial denaturation), followed by 26 cycles of denaturation at $95^{\circ} \mathrm{C}$ for 30 seconds, annealing for 30 seconds at $57^{\circ} \mathrm{C}$ for TGF- $\beta 1$ and at $58^{\circ} \mathrm{C}$ for glyceraldehyde 3-phosphate dehydrogenase, extension at $72^{\circ} \mathrm{C}$ for 30 seconds. The PCR products were visualized on a $2 \%$ (w/v) agarose gel containing $1 \mu \mathrm{g} / \mathrm{mL}$ ethidium bromide with a UV transilluminator (Gel Doc 2000, Bio-Rad).

\section{Flow cytometry analysis}

Cell cycling signals were analyzed using a Gallios ${ }^{\mathrm{TM}}$ Flow Cytometer (Beckman Coulter, Miami, FL). In this study, classic procedures were followed to evaluate propidium iodide (Beyotime Institute of Biotechnology, Shanghai, China), staining of DNA content. After 72 hours of transfection, cells were washed twice with PBS (pH 7.4) and detached from the wells with trypsin. The suspended cells were placed in sterilized centrifuge tubes and centrifuged at $1500 \mathrm{rpm}$ for 5 minutes using an Eppendorf centrifuge (Eppendorf GA, Hamburg, Germany), removing the supernatant. The cell 
pellet was then washed with PBS and resuspended with $0.5 \mathrm{~mL}$ of PBS (pH 7.4). The cell suspension was added into $5 \mathrm{~mL}$ of $75 \%$ ethanol with precooling at $-20^{\circ} \mathrm{C}$ (very slowly, drop by drop) and then fixed at $4{ }^{\circ} \mathrm{C}$ overnight, followed by centrifuge at $1000 \mathrm{rpm}$ for 5 minutes at $4^{\circ} \mathrm{C}$ to remove the ethanol. The cell pellet was washed twice with PBS $+1 \%$ bovine serum albumin and resuspended in $400 \mu \mathrm{L}$ PBS $+1 \%$ bovine serum albumin. After that, $50 \mu \mathrm{L}$ of $500 \mu \mathrm{g} / \mathrm{mL}$ propidium iodide was added into the cell suspension, followed by incubation at $37^{\circ} \mathrm{C}$ for 30 minutes before analysis by flow cytometer.

The cells were divided into four groups: group 1, treated with free pTGF- $\beta 1$; group 2 , treated with Lipofectamine $2000 /$ pTGF- $\beta 1$; group 3 , treated with CPEPS-pTGF- $\beta 1$ nanoparticles, and group 4 , treated with medium containing pTGF- $\beta 1$ protein.

\section{Statistical analysis}

The data were analyzed with both one-factor and twofactor analyses of variance. Student's $t$-test and the Fisher's protected least significance difference post hoc test were used to determine the significance (significance accepted at $P<0.01)$ of the difference between selected groups with SPSS statistics software (v15.0; SPSS Inc, Chicago, IL). The data were presented as the mean \pm standard error of the mean.

\section{Results}

\section{Characteristics of the CPEPS}

The GPC findings showed that the average molecular weights of the PEPS and CPEPS were $549 \mathrm{kDa}$ and $333 \mathrm{kDa}$, respectively. The amount of primary and secondary amino groups derived from spermine and the percentage of crosslinked spermine were as shown in Table 1. The findings showed that CPEPS was not cross-linked.

Qualitative functional group analysis of the CPEPS by Fourier transform infrared spectroscopy $(\mathrm{KBr})$ yielded peaks at $3410,1650,1460,1270$, and $1030 \mathrm{~cm}^{-1}$ (see Figure 4). Comparatively, the spectrum of the CPEPS revealed an obvious change at $3410 \mathrm{~cm}^{-1}$ (the presence of amine and -OH groups),

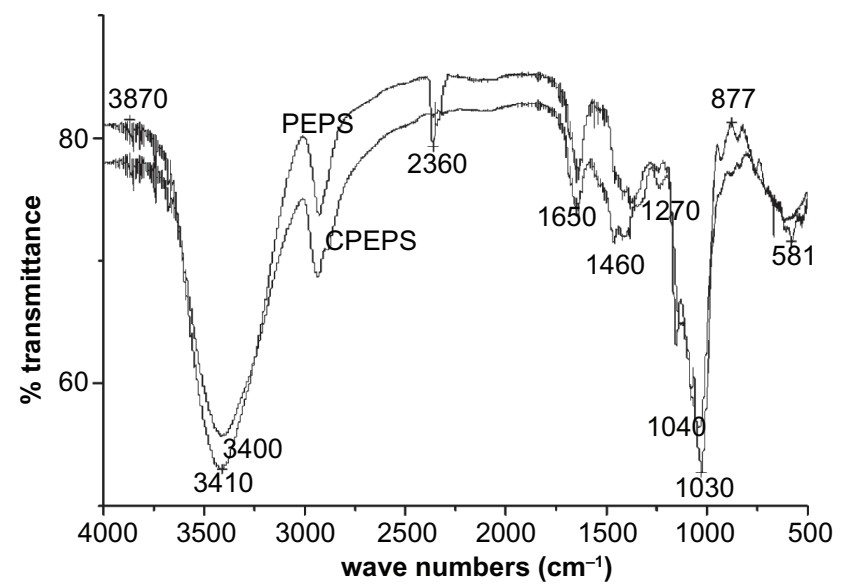

Figure 4 Fourier transform infrared spectra of polysaccharide of Pleurotus eryngii (PEPS) and cationized P. eryngii polysaccharide (CPEPS).

and peaks at $1650 \mathrm{~cm}^{-1}$ (indicating the existence of $-\mathrm{NH}_{2}$ ), $1270 \mathrm{~cm}^{-1}$ (indicating the $\mathrm{C}-\mathrm{O}$ group in an ester bond), ${ }^{39}$ and $1030 \mathrm{~cm}^{-1}$ (-OH stretching) as against the spectrum of PEPS. This demonstrated that the amino groups were successfully grafted onto the backbone of the polysaccharide.

Thin layer chromatography revealed that the monosaccharides in the PEPS mainly consisted of glucose, galactose, and mannose.

\section{Gel retardation effect of the CPEPS-pTGF- $\beta$ I nanoparticles}

Figure 5 shows the electrophoretic pattern of the tested CPEPSpTGF- $\beta 1$ nanoparticles with different CPEPS/pTGF- $\beta 1$ weight ratios. The nanoparticles with the lowest CPEPS/pTGF- $\beta 1$ weight ratio (1:5; well 2 of Figure 5) showed that a portion of the TGF- $\beta 1$ plasmids had detached itself from the nanoparticles and migrated into the gel, as demonstrated by a faint band corresponding to the location of the naked TGF- $\beta 1$ plasmid (well 1 of Figure 5). When the CPEPS/pTGF- $\beta 1$ weight ratio was increased to 10:1 (well 3 of Figure 5), there was no sign of plasmid migration across the agarose gel. This indicated that the complexation of pTGF- $\beta 1$ and CPEPS was strong enough to completely retard DNA migration. Accordingly, the CPEPSpTGF- $\beta 1$ complexes with weight ratios of 10:1, 20:1, and 30:1 were used in the subsequent transfection study.

Table I Amino group content and cross-linking of CPEPS

\begin{tabular}{lllllll}
\hline Polycation & $\begin{array}{l}\text { Nitrogen }^{\mathrm{a}} \\
(\mu \mathrm{mol} / \mathbf{m g})\end{array}$ & $\begin{array}{l}\text { Primary amines }^{\mathrm{b}} \\
(\mu \mathrm{mol} / \mathbf{m g})\end{array}$ & $\begin{array}{l}\text { Spermine }^{\mathrm{c}} \\
(\mu \mathrm{mol} / \mathbf{m g})\end{array}$ & $\begin{array}{l}\text { Secondary amines }^{\mathrm{d}} \\
(\mu \mathrm{mol} / \mathbf{m g})\end{array}$ & $\begin{array}{l}\text { Secondary to primary } \\
\text { amine ratio }^{2}\end{array}$ & $\begin{array}{l}\text { Cross-linked } \\
\text { spermine }^{\mathrm{e}}(\%)\end{array}$ \\
\hline CPEPS & $3.92 \pm 0.23$ & $1.24 \pm 0.09$ & $0.98 \pm 0.06$ & $2.94 \pm 0.18$ & $2.40 \pm 0.30$ & 0
\end{tabular}

Notes: a Determined by elemental analysis $(n=3)$; betermined by the trinitrobenzene sulfonic acid method $(n=3)$; ${ }^{c}$ calculated from elemental analysis (total nitrogen divided

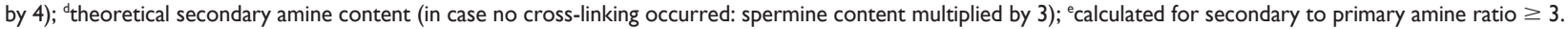
Abbreviation: CPEPS, cationized Pleurotus eryngii polysaccharide. 


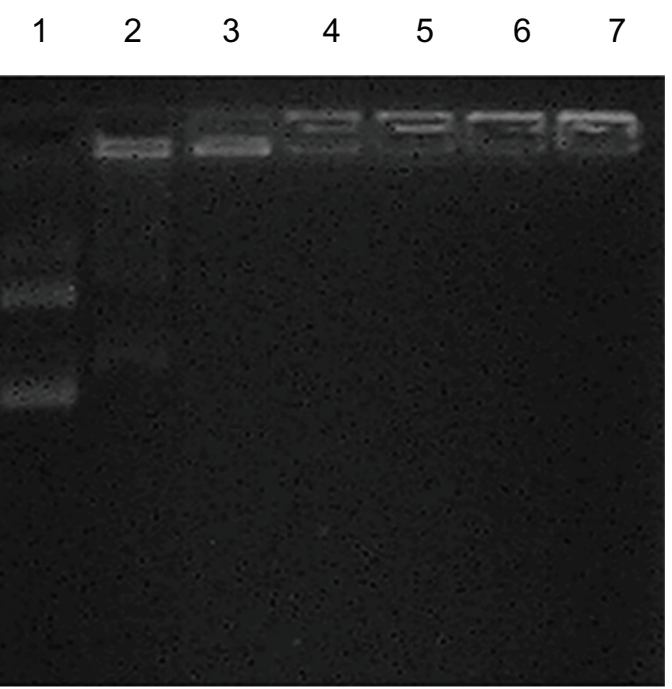

Figure 5 Agarose gel electrophoresis of the CPEPS-pTGF- $\beta$ I nanoparticles. Notes: Well I, free pTGF- $\beta$ I; wells $2-7$, CPEPS-pTGF- $\beta$ I nanoparticles with various weight ratios of CPEPS/PTGF- $\beta$ I (from left to right: 5:I, 10:1, 20:1, 30:1, 60:1, and 80:1).

Abbreviations: CPEPS, cationized Pleurotus eryngii polysaccharide; PTGF- $\beta$ I, plasmid encoding transforming growth factor beta-I.

\section{Zeta potential}

The zeta potential of the original CPEPS was $+19.4 \pm 0.2 \mathrm{mV}$ (mean \pm standard error for 15 runs of the same sample; see Figure 6). In contrast, the zeta potential of the naked pTGF- $\beta 1$ was $-42.1 \pm 0.3 \mathrm{mV}$ (Figure 6). At the three different ratios of CPEPS/pTGF- $\beta 1$ (10:1, 20:1 and 30:1), the zeta potential changed from a negative value to a positive value and increased to $+17.0 \pm 0.2 \mathrm{mV},+17.4 \pm 0.1 \mathrm{mV}$, and $+19.2 \pm 0.2 \mathrm{mV}$, respectively.

\section{Particle size distribution and morphology}

DLS demonstrated the various sizes of the nanoparticles with CPEPS/pTGF- $\beta 1$ weight ratios of 10:1, 20:1, and 30:1. The size distribution of the nanoparticles with a CPEPS/pTGF- $\beta 1$ weight ratio of $20: 1$ ranged from $29.2 \mathrm{~nm}$ to $168.5 \mathrm{~nm}$, with an average diameter of $80.8 \mathrm{~nm}$ (Figure 7A), whereas the average sizes of the other two nanoparticle groups were $248.3 \mathrm{~nm}$ (10:1) and $151.1 \mathrm{~nm}(30: 1)$, respectively (Table 2).

The TEM measurement showed that the monodispersed nanoparticles (CPEPS/pTGF- $\beta 1$ weight ratio of 20:1) had a spherical shape and a size distribution within a relatively narrow range (30-50 nm) (Figure 7B).

\section{Cytotoxicity of the CPEPS-pTGF- $\beta$ I nanoparticles}

As shown in Figure 8, the result demonstrated that the CPEPS-pTGF- $\beta 1$ nanoparticles yielded comparative or even higher cell viability than that of Lipofectamine 2000 and branched PEI ( $25 \mathrm{kDa})$, indicating that the CPEPS-pTGF- $\beta 1$ nanoparticles were safe for MSCs.

\section{In vitro gene transfection}

The TEM images of MSCs before and after transfection are shown in Figure 9.

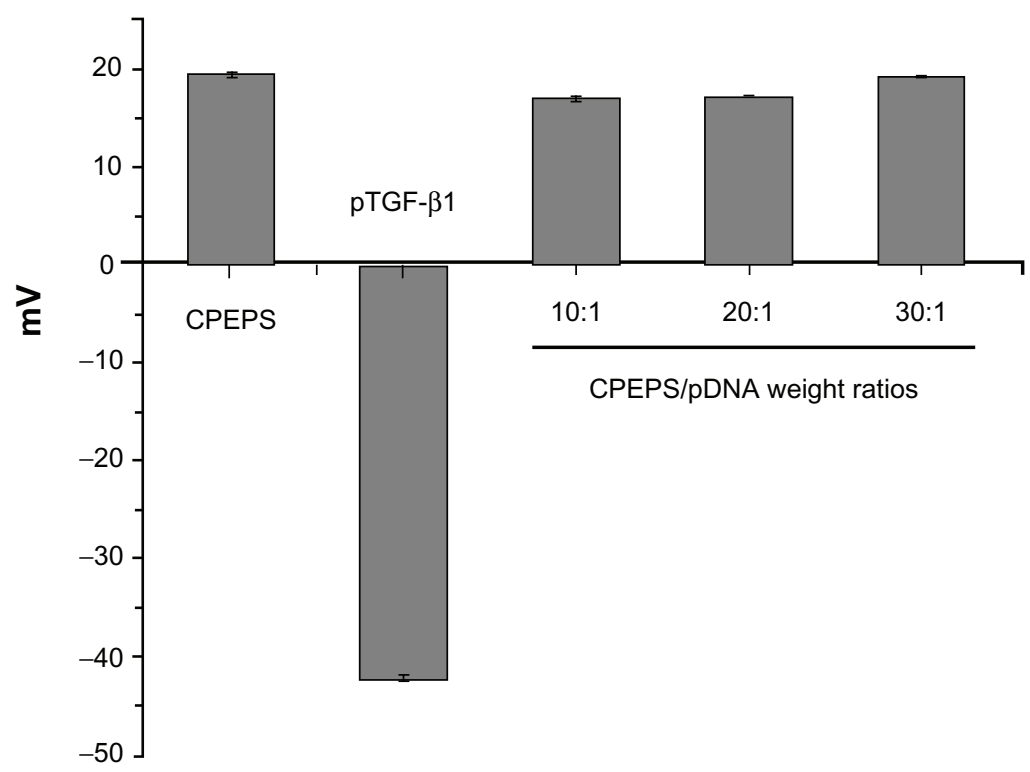

Figure 6 The zeta potentials of free pTGF- $\beta$ I, CPEPS, and CPEPS combined with different amounts of pTGF- $\beta$ I to yield the following CPEPS/pTGF- $\beta$ I weight ratios: I0:I, 20:1, and 30:1.

Note: The values are the means \pm standard error of the mean of three experiments.

Abbreviations: TGF- $\beta$ I, transforming growth factor beta-I; PTGF- $\beta$ I, plasmid encoding TGF- $\beta$ I; CPEPS, cationized P. eryngii polysaccharide. 
A

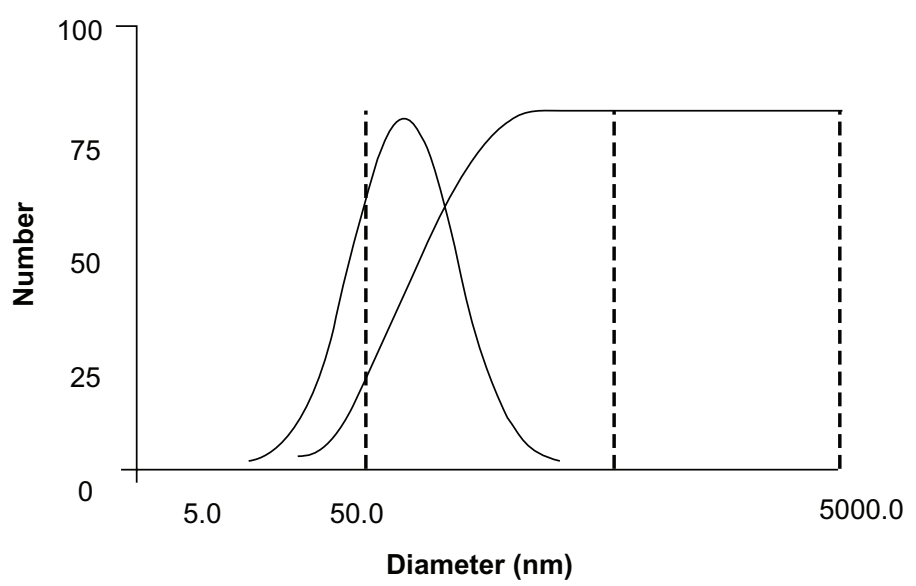

B

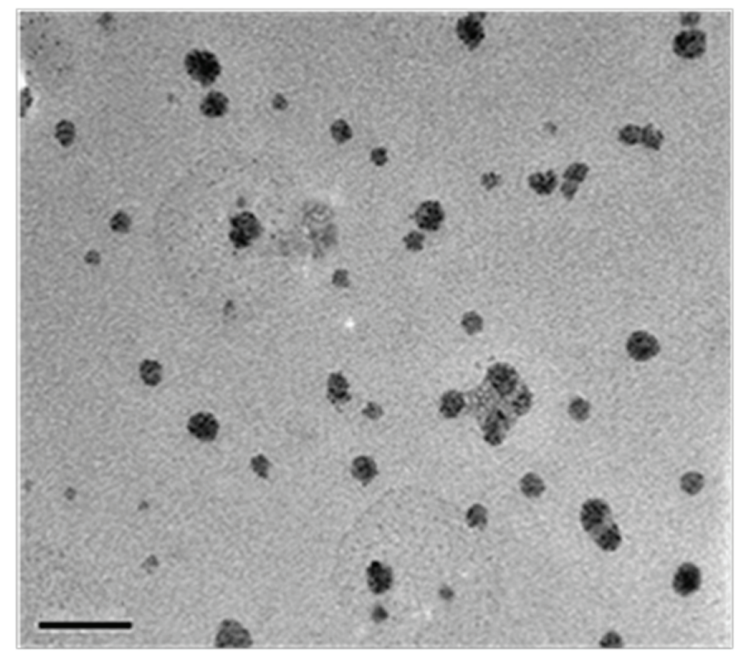

Figure 7 Particle size distribution and morphology. (A) The particle size distribution of the CPEPS/PTGF- $\beta$ I nanoparticles with a weight ratio of 20:I; (B) transmission electron microscopy image of the CPEPS/PTGF- $\beta$ I nanoparticles with a weight ratio of 20:1.

Abbreviations: CPEPS, cationized Pleurotus eryngii polysaccharide; PTGF- $\beta$ I, plasmid encoding transforming growth factor beta-I.

Among the three groups of different CPEPS/pTGF- $\beta 1$ weight ratios $(10: 1,20: 1$, and 30:1), the optimal TGF- $\beta 1$ expression was recorded for a CPEPS/pTGF- $\beta 1$ weight ratio of 20:1 (Figure 10A). Statistically, the CPEPSpTGF- $\beta 1$ nanoparticles with a CPEPS/pTGF- $\beta 1$ weight ratio of 20:1 revealed a significantly higher transfection effect than that of PEI ( $25 \mathrm{kDa})(P=0.002$, Student's $t$-test $)$ and Lipofectamine $2000(P=0.006$, Student's $t$-test $)$, the

Table 2 The size distribution of nanoparticles with CPEPS/PTGF$\beta I$ weight ratios of I0:I, 20:1, and 30:I

\begin{tabular}{llll}
\hline $\begin{array}{l}\text { CPEPS/pTGF- } \beta \text { I } \\
\text { weight ratios }\end{array}$ & $10: 1$ & $20: 1$ & $30: 1$ \\
\hline $\begin{array}{l}\text { Particle size } \\
\text { (means } \pm \text { SEM, } n m \text { ) }\end{array}$ & $248.3 \pm 7.4$ & $80.8 \pm 6.8$ & $151.1 \pm 7.2$ \\
\hline
\end{tabular}

Abbreviations: CPEPS, cationized Pleurotus eryngii polysaccharide; PTGF- $\beta$ I, plasmid encoding transforming growth factor beta-I; SEM, standard error of the mean. current gold standard of commercial transfection reagents (Figure 10B).

\section{mRNA expression level of TGF- $\beta$ I}

As shown in Figure 11, the mRNA expression level of TGF- $\beta 1$ in CPEPS-pTGF- $\beta 1$ nanoparticle-transfected MSCs (well 1 in Figure 11) was notably higher than that of MSCs transfected with free pTGF- $\beta 1$ (well 2 in Figure 11) and also slightly higher than that of MSCs transfected with Lipofectamine 2000 (well 3 in Figure 11).

\section{Flow cytometry analysis}

As shown in Figure 12, the results of the flow cytometry of propidium iodide-stained cells demonstrated that the percentage of cells in the G1 phase for group $1(85.20 \%$, Figure 12A) was the lowest with the highest percentage being that of group 3 $(92.38 \%$, Figure 12C). However, the percentage of cells in the 


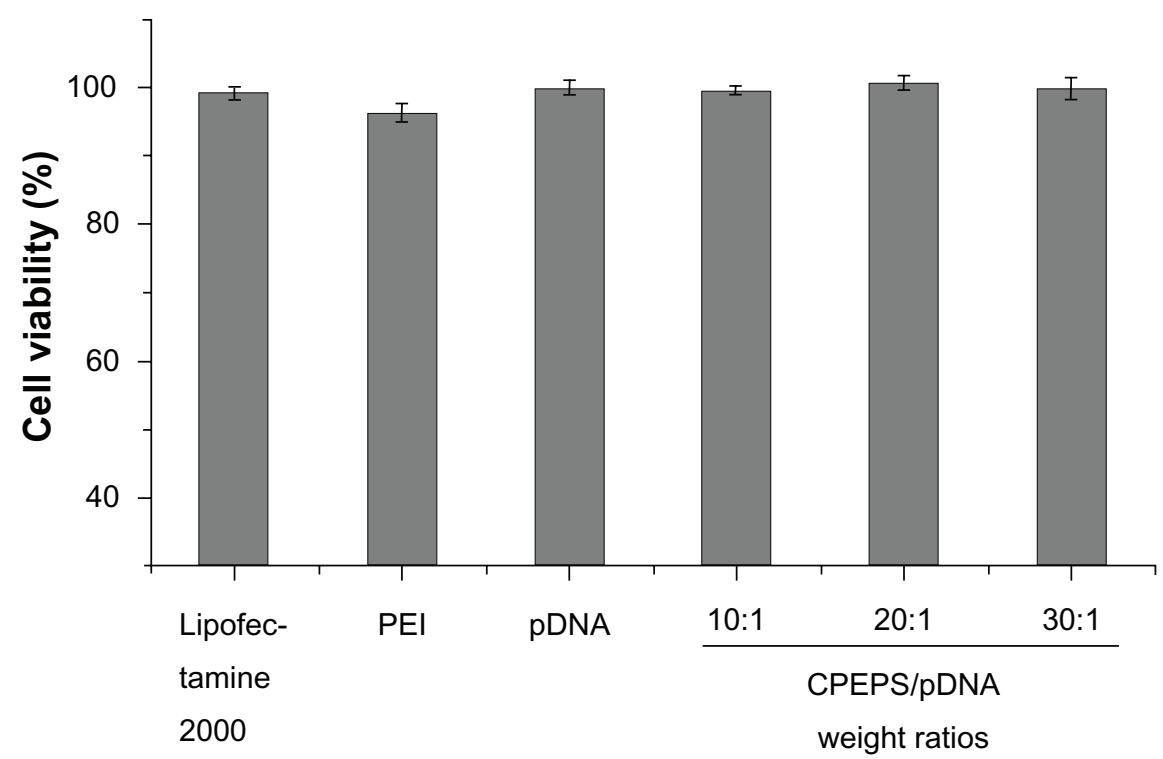

Figure 8 Cytotoxicity assay. From left to right: Lipofectamine ${ }^{\mathrm{TM}} 2000$; polyethylenimine ( $\left.25 \mathrm{kDa}\right)$; free plasmid; CPEPS-pTGF- $\beta$ I nanoparticles with CPEPS/pTGF- $\beta$ I weight ratios of I0:I, 20:I, and 30:I.

Note: The values are the means \pm standard error of the mean of three experiments.

Abbreviations: CPEPS, cationized Pleurotus eryngii polysaccharide; PEI, polyethylenimine; pTGF- $\beta$ I, plasmid encoding transforming growth factor beta-I.

S phase for group $1(12.35 \%)$ was higher than that of the other three groups (group 2 [Figure 12B]: 7.55\%; group 3: 7.62\%, and group 4: 8.4\% [Figure 12D]). Interestingly, there were no cells in the G2 phase for group 3.
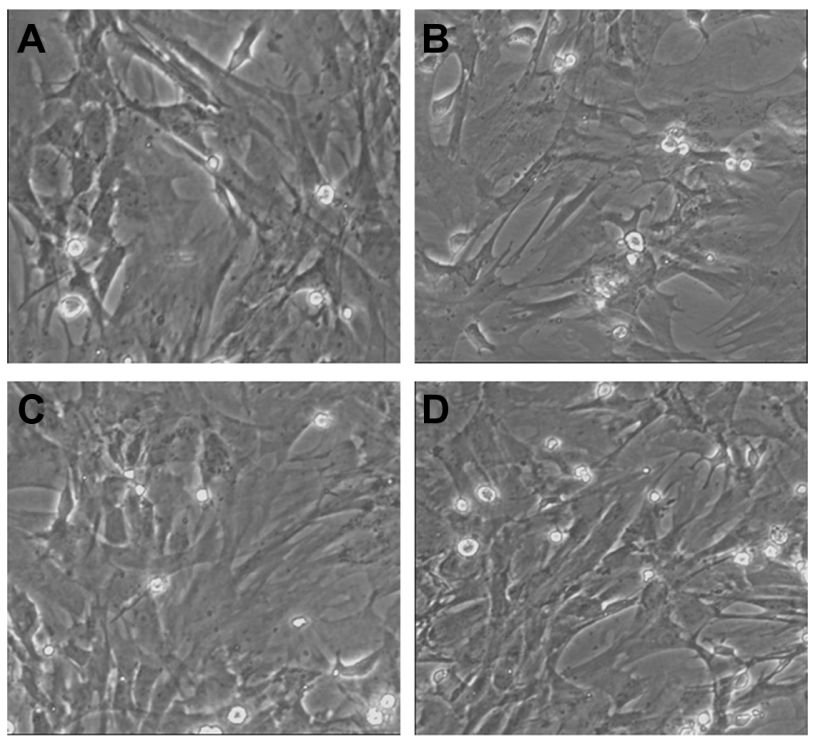

Figure 9 Transmission electron microscopy (TEM) images of MSCs before and after transfection. (A) TEM image of mesenchymal stem cells before transfection; (B-D) TEM images of mesenchymal stem cells after transfection by CPEPSPTGF- $\beta$ I nanoparticles with CPEPS/PTGF- $\beta$ I weight ratios of I0:1, 20:1, and 30:1, respectively.

Abbreviations: CPEPS, cationized Pleurotus eryngii polysaccharide; PTGF- $\beta$ I, plasmid encoding transforming growth factor beta-I.

\section{Discussion}

In this study, PEPS was used as a gene delivery material for the first time. PEPS was a promising candidate for gene delivery after proper modification due to its advantages, including biocompatibility, biodegradability, nontoxicity, and ease of chemical modification.

Generally, the molecular weights of polymers are determined by GPC, which is also known as size-exclusion chromatography, equipped with either an $\mathrm{RID}^{32,60}$ or a lightscattering detector. ${ }^{20,24}$ Despite the increasingly widespread application of DLS, GPC equipped with RID has equally also been used to measure the molecular weights of polymers in many recent studies. ${ }^{32,60}$ Based on other studies and the limited experimental conditions in the laboratory, a RID (Shimadzu GPC system-equipped Shimadzu RID-10 A) was used to determine the molecular weights of PEPS and CPEPS. The findings revealed a drastic decease in the molecular weight of CPEPS (549 $\mathrm{kDa}$ ) as compared to that of PEPS $(333 \mathrm{kDa})$. This could possibly be due to the extensive aminolysis of PEPS during the conjugation reaction. ${ }^{38,58}$

In previous studies, ${ }^{38,58}$ nuclear magnetic resonance (NMR) was employed to further characterize the structure of the polysaccharide. In this work, ${ }^{1} \mathrm{H}$ NMR spectra were recorded on a $400 \mathrm{MHz}$ Bruker AV-400 NMR spectrometer (Bruker, Madison, WI) to characterize the structure of PEPS and CPEPS. Unfortunately, no valuable information could be obtained (data not shown). In some published reports ${ }^{58,61,62}$ the 
A

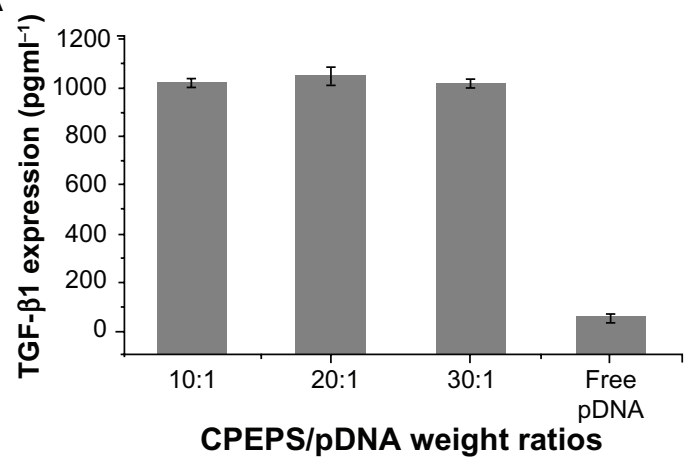

B

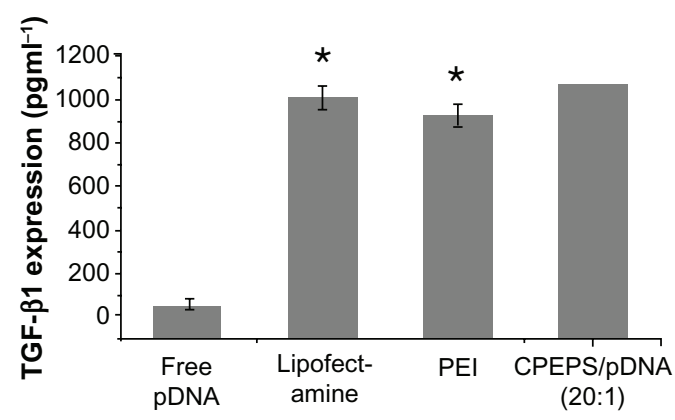

Figure 10 TGF- $\beta$ I protein released into the medium from mesenchymal stem cells 72 hours after treatment with CPEPS-pTGF- $\beta$ I nanoparticles. (A) TGF- $\beta$ I protein concentrations in the medium with various weight ratios of CPEPS to PTGF- $\beta$ I: 10:I (first bar), 20:I (second bar), and 30:I (third bar), as well as in free plasmid DNA (fourth bar). (B) A comparison of TGF- $\beta$ I expression levels: free plasmid DNA (first bar); Lipofectamine ${ }^{\mathrm{TM}} 2000$ (second bar); polyethylenimine $(25 \mathrm{kDa}$, third bar); and CPEPS-pTGF- $\beta$ I nanoparticles with a CPEPS/pTGF- $\beta$ I weight ratio of 20: I (fourth bar).

Note: The values are the means \pm standard error of the mean of three experiments. Abbreviations: TGF- $\beta$ I, transforming growth factor beta-I; PTGF- $\beta$ I, plasmid encoding TGF- $\beta$ I; CPEPS, cationized Pleurotus eryngii polysaccharide; PEI, polyethylenimine.

samples had molecular weights less than $100 \mathrm{kDa}$ as against the results of this study $(>100 \mathrm{kDa})$. It is possible that the molecular weights of the samples were beyond the sensitivity of the NMR spectrometer. The exact reason is still unknown, and it will be explored in our future study. According to some researchers, ${ }^{39,60}$ it was acceptable to combine the use of trinitrobenzene sulfonic acid, total nitrogen determination, and Fourier transform infrared spectroscopy to characterize the CPEPS.

Spermine, an amino compound with two primary amino groups and two secondary amino groups on each molecule, was chemically grafted onto PEPS to obtain CPEPS. ${ }^{58}$ The quantity of the total amount of nitrogen per microgram of CPEPS indicated the amount of spermine grafted on the backbone of PEPS. As spermine was conjugated to the polysaccharide via one of its primary amino groups, the conjugated primary amino group
TGF- $\beta 1$

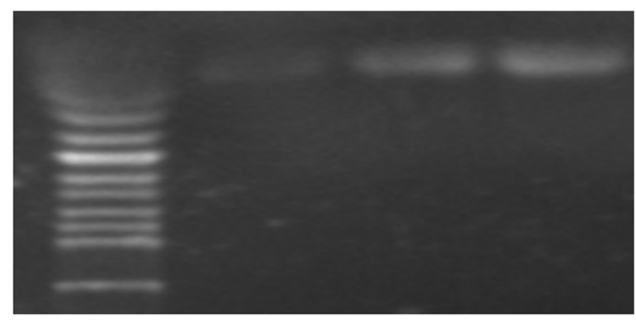

\section{GAPDH}

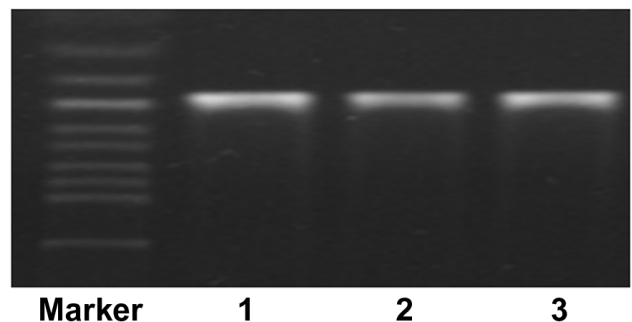

Figure II Messenger RNA expression of TGF- $\beta$ I in mesenchymal stem cells (MSCs).

Notes: Well I, MSCs transfected with free PTGF- $\beta$ I; well 2, MSCs transfected with Lipofectamine ${ }^{\mathrm{TM}}$ 2000/PTGF- $\beta$ I; well 3, MSCs transfected with CPEPSPTGF- $\beta$ I nanoparticles.

Abbreviations: TGF- $\beta$ I, transforming growth factor beta-I; CPEPS, cationized Pleurotus eryngii polysaccharide; PTGF- $\beta$ I, plasmid encoding TGF- $\beta$ I; GAPDH, glyceraldehyde 3-phosphate dehydrogenase.

became a secondary amine after conjugation. ${ }^{38}$ Cross-linking was possible via the remaining primary amine of spermine. In this study, no cross-linking was observed (Table 1), indicating good control of the reaction conditions. Significantly, a low degree of cross-linking was desirable in this application.

The study investigated the monosaccharide content of the PEPS via preliminary thin layer chromatography analysis and found that D-glucose was the major monosaccharide component; the other components were galactose and mannose. The results were in agreement with previous studies. ${ }^{50}$ It was speculated that because D-glucose was the major monosaccharide in PEPS, the monomer was more likely to be grafted with spermine. It was also likely that the spermine might be linked to the other monosaccharide components. In a related study, various polysaccharides (pullulan, dextran, and mannan) with different cationization degrees were used to transfect MSCs in order to examine the factors affecting transfection. ${ }^{63}$ The findings showed that the gene expression level was closely related to the type of cationized polysaccharide. The exact composition of PEPS monosaccharides, which are the major contributors of cationization, will be addressed in future works.

Gel electrophoresis showed that the cationized polysaccharide could successfully incorporate TGF- $\beta 1$ plasmid. The complexation of CPEPS and TGF- $\beta 1$ plasmid was CPEPScontent dependent, with a greater CPEPS/pTGF- $\beta 1$ weight ratio resulting in better plasmid incorporation. 

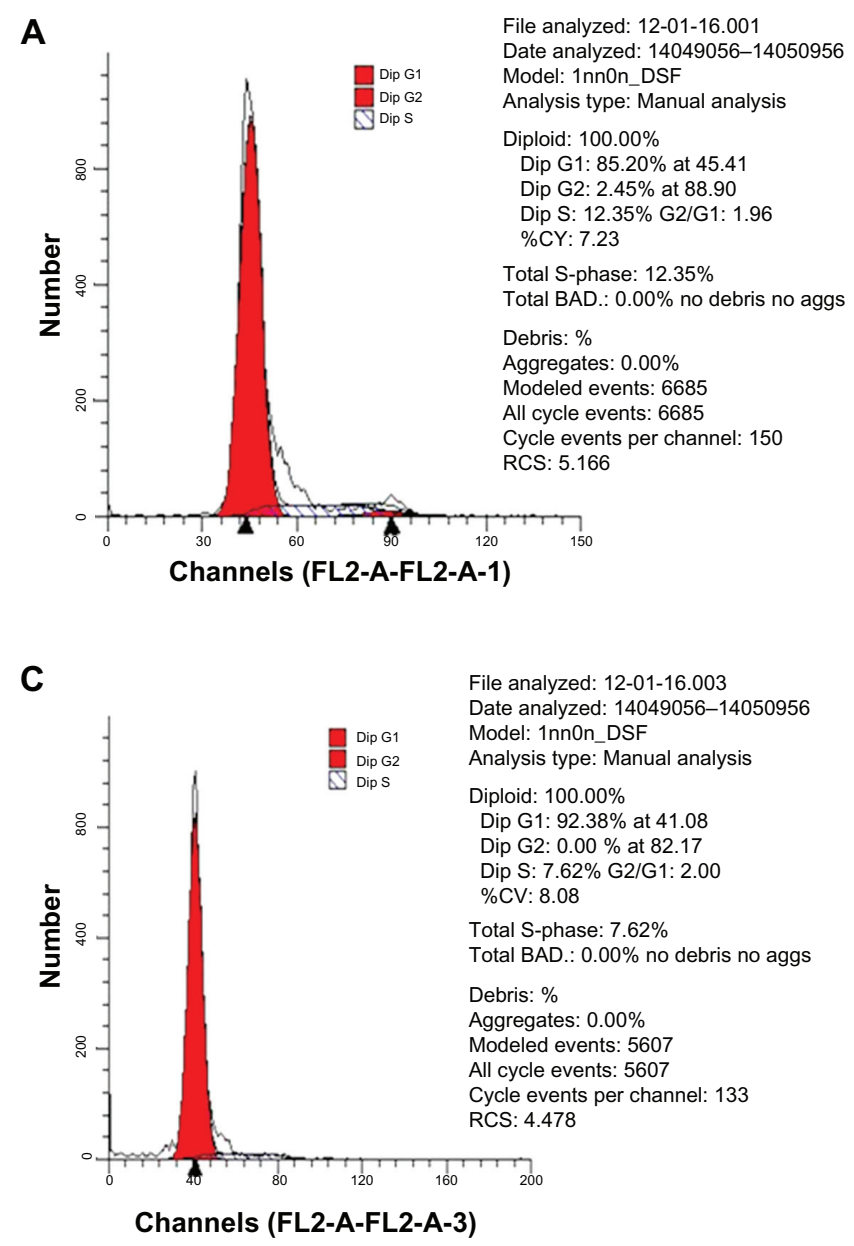
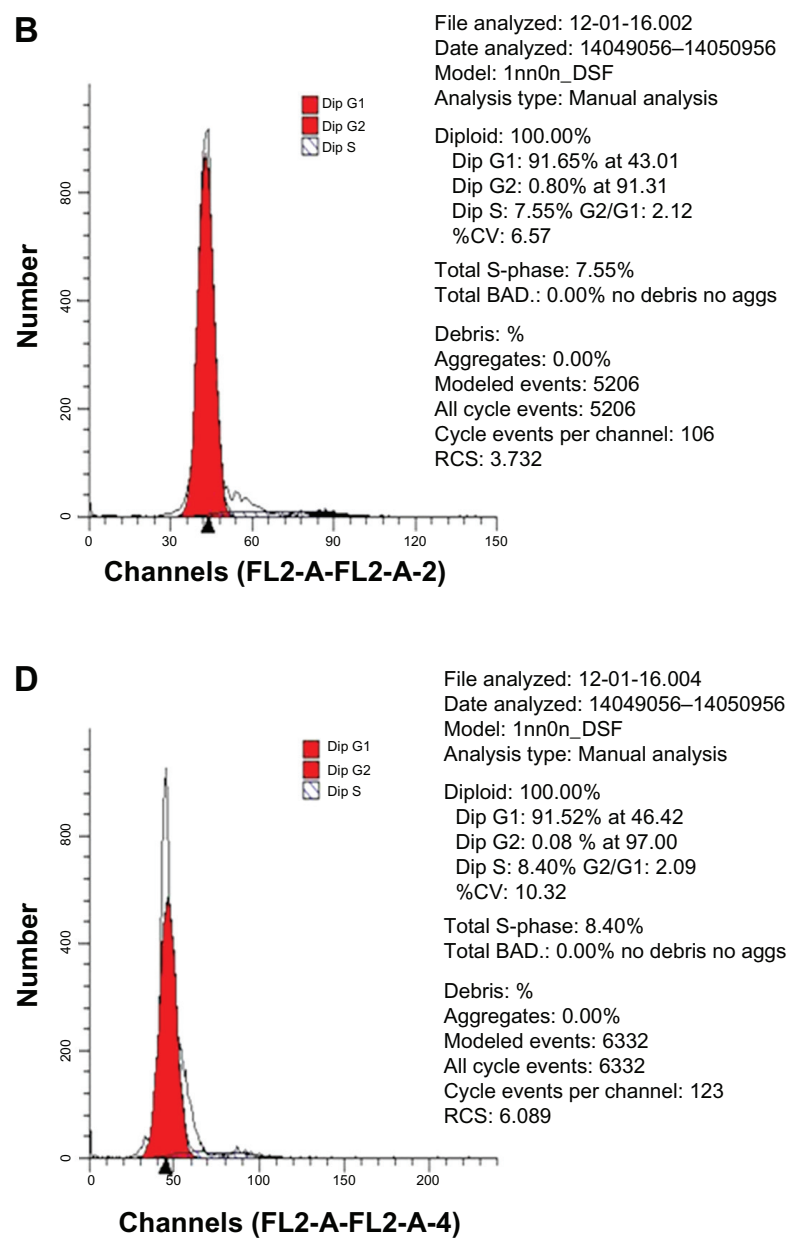

Figure 12 Flow cytometry of propidium iodide-stained mesenchymal stem cells (MSCs). (A) MSCs treated with plasmid TGF- $\beta$ I; (B) MSCs treated with Lipofectamine ${ }^{\mathrm{TM}}$ 2000/pTGF- $\beta$ I; (C) MSCs treated with CPEPS-pTGF- $\beta$ I nanoparticles; (D) MSCs treated with medium containing PTGF- $\beta$ I protein.

Abbreviations: TGF- $\beta$ I, transforming growth factor beta-I; PTGF- $\beta$ I, plasmid encoding TGF- $\beta$ I; CPEPS, cationized Pleurotus eryngii polysaccharide.

It is well known that DNA charge reversal is one of the basic requirements for the transfection of cells. Interestingly, the zeta potentials of the three different CPEPSpTGF- $\beta 1$ nanoparticles were almost the same as that of the original polysaccharide $(+19.4 \pm 0.2 \mathrm{mV})$ and statistically insignificant (see Figure 6.) This implies that the negatively charged plasmids were successfully combined with the positively charged polysaccharide to form nanoparticles of more positive charges on its outer surface. Therefore, the value of the positive charges on the surface of the nanoparticles will be comparable to that of the original CPEPS. This point will be further investigated in future studies.

The particle size values provided by TEM $(30-50 \mathrm{~nm}$, Figure 7B) and DLS (29.2 168.5 nm) were quite different (Table 2 and Figure 7A). A possible reason could be that the DLS and TEM had various determination conditions: samples measured by DLS were in suspended form, whereas dried particles were observed under TEM. In summary, the
CPEPS-pTGF- $\beta 1$ complex had a nanoscaled particle size. Interestingly, these findings showed that the average particle size of the formulated nanoparticles (CPEPS/pTGF- $\beta 1$ weight ratio of 20:1) was $80.8 \mathrm{~nm}$ in diameter, which was much smaller than the sizes reported in previous studies (cationized gelatin ${ }^{15}$ and chitosan ${ }^{25}$ nanoparticles with an average size of approximately $172 \mathrm{~nm}$ in diameter and $250 \mathrm{~nm}$ in diameter were produced, respectively). However, the average size of the nanoparticles with a CPEPS/pTGF- $\beta 1$ weight ratio of 30:1 was $151.1 \mathrm{~nm}$ which is obviously larger than that of the 20:1 nanoparticles. This large particle size suggested that excess cationic polysaccharide might acquire a greater positive zeta potential, but it could also cause redundant CPEPS coacervation on the particle surface resulting in a particle size increase. This is unfavorable for cellular uptake.

Low cytotoxicity is one of the basic requirements for a safe and effective gene carrier. The outcome of the MTT test showed that the CPEPS-pTGF- $\beta 1$ nanoparticles exhibited 
an exceptional safety profile (Figure 8). It is likely that the intracellular degradability of the polymer was responsible for the low cytotoxicity of CPEPS. ${ }^{49}$ Inside the cells, the CPEPS could be degraded to different kinds of monosaccharides and oligoamines, which were easily metabolized, hence nontoxic. ${ }^{64}$ Essentially, the CPEPS-pTGF- $\beta 1$ nanoparticles prepared in this study were safe for MSCs.

Cell transfection efficiency is the key index in evaluating the properties of nonviral gene carriers. The results of the CPEPS-pTGF- $\beta 1$ nanoparticles with a weight ratio of 20:1 (80.8 $\mathrm{nm}$ on average) showed the highest transfection efficiency (Figure 10A). This means that the smaller size of the nanoparticles facilitated the movement of the particles through membranes. In addition, when the CPEPS/pTGF- $\beta 1$ weight ratio was lower than 20:1, it could possibly lead to an incomplete encapsulation of the negatively charged naked pTGF- $\beta 1$, resulting in a relatively large particle size $(248.3 \mathrm{~nm})$ that probably hindered the process of cellular uptake. This assertion was also supported by the gel retardation assay (Figure 5). It was observed that there was less tendency for the plasmid to migrate as the CPEPS/pTGF- $\beta 1$ weight ratio increased. The free plasmid DNA showed the greatest migration towards the positive pole. This implies that the complex with a weight ratio of 10:1 had an inadequate amount of cationic polysaccharide. In the case of the nanoparticles with a CPEPS/pTGF- $\beta 1$ weight ratio greater than 20:1, the reduced TGF- $\beta 1$ expression could possibly be due to a larger particle size $(151.1 \mathrm{~nm})$, as well as to the strong bond of attraction between the CPEPS and pTGF- $\beta 1$. This would have prevented the release of pTGF- $\beta 1$ from the nanoparticles in a timely and complete manner once the nanoparticles entered the cells. Additionally, a high CPEPS/pTGF- $\beta 1$ weight ratio might lead to the state of free CPEPS that could competitively inhibit the interaction between CPEPS-pTGF- $\beta 1$ nanoparticles and cell membrane. ${ }^{39}$ Further investigations would be needed to provide a deeper understanding of the MSC transfection mechanisms with respect to the CPEPS/pTGF- $\beta 1$ weight ratio.

Interestingly, the CPEPS-pTGF- $\beta 1$ nanoparticles (weight ratio of 20:1) showed a significantly enhanced transfection effect as compared to those of PEI (25 kDa), $(P=0.002$, Student's $t$-test $)$ and Lipofectamine $2000(P=0.006$, Student's $t$-test). This was possible because CPEPS could condense the TGF- $\beta 1$ plasmid to a small size $(80.8 \mathrm{~nm}$ on average), which facilitated the process of cellular uptake. At the same time, the positive charge on the surface of the nanoparticle $(+17.4 \pm 0.1 \mathrm{mV})$ promoted the interaction with the negatively charged cell membranes. It is a well-known fact that polysaccharides can readily be transported to cells by known biological processes, which might greatly contribute to the success of the transfection. ${ }^{38}$

In the study, long-term (72-hour) expression of TGF- $\beta 1$ by MSCs was also investigated. In a related study ${ }^{64}$ immunofluorescence staining was conducted to check if the stem cells had differentiated after transfection. The findings of that study showed that the transfection was transient. In this study, the results supported that, and after transfection stem cells still maintained mesenchymal lineage properties (data not shown). This could also be supported by the TEM images of MSCs before and after transfection, which exhibited no obvious morphological changes after transfection. Longer-term (more than 72-hour) transfection investigation will be addressed in future works.

Reverse transcriptase polymerase chain reaction was carried out to reflect the transfection effect of CPEPS-pTGF- $\beta 1$ nanoparticles from the mRNA expression level of TGF- $\beta 1$, and the result was in agreement with that revealed by enzymelinked immunosorbent assay, indicating the high transfection effect of CPEPS-pTGF- $\beta 1$ nanoparticles and their superiority over Lipofectamine 2000.

It is well known that the $\mathrm{S}$ phase is the cell cycle phase for DNA synthesis which prepares the cells for mitosis, and the G1 phase is the cell stage after mitosis to the beginning of the $\mathrm{S}$ phase. So the cells moving from the $\mathrm{S}$ to the $\mathrm{G} 1$ phase indicated a tendency of differentiation. Flow cytometry analysis revealed that cells transfected with CPEPS-pTGF- $\beta 1$ nanoparticles had low proliferation but showed a tendency of differentiation. This could possibly be due to the effect of TGF- $\beta 1$ on MSCs, because TGF- $\beta 1$ has the ability to induce chondrogenesis of MSCs. ${ }^{65}$ Further investigation of this aspect will be addressed in future studies.

\section{Conclusion}

In this study, a polysaccharide isolated from the edible mushroom $P$. eryngii was chemically modified with spermine for the first time to obtain CPEPS, out of which CPEPS-pTGF- $\beta 1$ nanoparticles were then prepared. Gel retardation assay showed that CPEPS-pTGF- $\beta 1$ nanoparticles possessed the ability to prevent the plasmid DNA from migrating when the CPEPS/ pTGF- $\beta 1$ weight ratio increased to 10:1. Varying the CPEPS to TGF- $\beta 1$ plasmid weight ratio affected the TGF- $\beta 1$ expression significantly, with the highest transfection efficiency noted at the CPEPS/pTGF- $\beta 1$ weight ratio of $20: 1$. In addition, the CPEPS-pTGF- $\beta 1$ nanoparticles (weight ratio of 20:1) showed significantly enhanced transfection efficiency compared with that of Lipofectamine 2000. Cytotoxicity assay revealed that the CPEPS/pTGF- $\beta 1$ nanoparticles were 
less toxic than both PEI (25 kDa) and Lipofectamine 2000. Furthermore, the mRNA expression level of TGF- $\beta 1$ in MSCs transfected by CPEPS-pTGF- $\beta 1$ nanoparticles was significantly higher than that of free plasmid DNA-transfected MSCs and slightly elevated compared with that of Lipofectamine ${ }^{\mathrm{TM}}$ 2000-transfected MSCs. Flow cytometry analysis revealed that $92.38 \%$ of MSCs were arrested in the G1 phase after transfection with CPEPS-pTGF- $\beta 1$ nanoparticles, indicating a tendency of differentiation. All of these findings support the fact that the CPEPS-pTGF- $\beta 1$ nanoparticles could be developed into a promising gene delivery system in the near future.

\section{Acknowledgments}

This work was supported by the National Natural Science Foundation of China (30772661, 30973677, and 81072586), Special Funds for 333 Projects (BRA2010138), and IndustryUniversity-Research Institution Cooperation (BY2009141) in Jiangsu Province.

The authors are grateful to Caleb Kesse Firempong at Jiangsu University for English editing. The authors also thank the University Ethics Committee for their kind guidance with regard to the animal experiments.

\section{Disclosure}

There was no financial involvement with any organization or entity with a financial interest in or financial conflict with the subject matter or materials discussed in the paper.

\section{References}

1. Rubanyi GM. The future of human gene therapy. Mol Aspects Med. 2001;22:113-142.

2. Li S, Huang L. Non-viral gene therapy: promises and challenges. Gene Ther. 2000;7:31-34.

3. Li S, Ma Z. Nonviral gene therapy. Curr Gene Ther. 2001;1: 201-226.

4. Vile RG, Russell SJ, Lemoine NR. Cancer gene therapy: hard lessons and new courses. Gene Ther. 2000;7:2-8.

5. Nishikawa M, Huang L. Non-viral vectors in the new millennium: delivery barriers in gene transfer. Hum Gene Ther. 2001;12:861-870.

6. Han S, Mahato RI, Sung YK, Kim SW. Development of biomaterials for gene therapy. Mol Ther. 2000;2:302-317.

7. Eliyahu H, Joseph A, Azzam T, Barenholz Y, Domb AJ. Dextranspermine based polyplexes - evaluation of transgene expression and of local and systemic toxicity in mice. Biomaterials. 2006;27:1636-1645.

8. Phillips JE, Gersbach CA, Garcia AJ. Virus-based gene therapy strategies for bone regeneration. Biomaterials. 2007;28:211-229.

9. Daya S, Berns KI. Gene therapy using adeno-associated virus vectors. Clin Microbiol Rev. 2008;21:583-593.

10. Zaiss AK, Muruve DA. Immune responses to adeno-associated virus vectors. Curr Gene Ther. 2005;5:323-331.

11. Dani SU. The challenge of vector development in gene therapy. Braz J Med Biol Res. 1999;32:133-145.

12. Hu QJ, Zuo P, Shao B, et al. Administration of non-viral gene vector encoding rat $\beta$-defensin-2 ameliorates chronic Pseudomonas aeruginosa lung infection in rats. J Gene Med. 2010;12:276-286.
13. Merdan T, Kopeek J, Kissel T. Prospects for cationic polymers in gene and oligonucleotide therapy against cancer. Adv Drug Deliv Rev. 2002; 54:715-758.

14. De Smedt SC, Demeester J, Hennink WE. Cationic polymer based gene delivery systems. Pharm Res. 2000;17:113-126.

15. Xu XM, Capito RM, Spector M. Delivery of plasmid IGF-1 to chondrocytes via cationized gelatin nanoparticles. J Biomed Mater Res, Part A. 2008;84:73-83.

16. Mann A, Richa R, Ganguli M. DNA condensation by poly L-lysine at the single molecule level: role of DNA concentration and polymer length. J Control Release. 2008;125:252-262.

17. Zhang X, Oulad-Abdelghani M, Zelkin AN, et al. Poly(L-lysine) nanostructured particles for gene delivery and hormone stimulation. Biomaterials. 2010;31:1699-1706.

18. Lv HT, Zhang SB, Wang B, Cui SH, Yan J. Toxicity of cationic lipids and cationic polymers in gene delivery. $J$ Control Release. 2006;114:100-109.

19. Godbey WT, Wu KK, Mikos AG. Poly(ethylenimine) and its role in gene delivery. J Control Release. 1999;60:149-160.

20. He F, Wang CF, Jiang T, Han B, Zhuo RX. Poly[(5-methyl-5allyloxycarbonyl-trimethylene carbonate)-co-(5,5-dimethyl-trimethylene carbonate)] with Grafted Polyethylenimine as Biodegradable Polycations for Efficient Gene Delivery. Biomacromolecules. 2010;11: 3028-3035.

21. Sun YX, Zhang XZ, Cheng H, Cheng SX, Zhuo RX. A low-toxic and efficient gene vector: carboxymethyl dextran-graft-polyethylenimine. J Biomed Mater Res. Part A. 2008;84:1102-1110.

22. Nagasaki T, Hojo M, Uno A, et al. Long-term expression with a cationic polymer derived from a natural polysaccharide: schizophyllan. Bioconjug Chem. 2004;15:249-259.

23. Jo J, Ikai T, Okazaki A, Yamamoto M, Hirano Y, Tabata Y. Expression profile of plasmid DNA by spermine derivatives of pullulan with different extents of spermine introduced. J Control Release. 2007;118: 389-398.

24. Malmo J, Vårum KM, Strand SP. Effect of chitosan chain architecture on gene delivery: comparison of self-branched and linear chitosans. Biomacromolecules. 2011;12:721-729.

25. Xu XM, Capito RM, Spector M. Plasmid size influences chitosan nanoparticle mediated gene transfer to chondrocytes. J Biomed Mater Res, Part A. 2008;84:1038-1048.

26. Peng SF, Yang MJ, Su CJ, Chen HL, Lee PW. Effects of incorporation of poly ( $\gamma$-glutamic acid) in chitosin/DNA complex nanoparticles on cellular uptake and transfection efficiency. Biomaterials. 2009;30: 1797-1808.

27. Thanou M, Florea BI, Geldof M, Junginger HE, Borchard G. Quaternized chitosan oligomers as novel gene delivery vectors in epithelial cell lines. Biomaterials. 2002;23:153-159.

28. Corsi K, Chellat F, Yahia L, Fernandes JC. Mesenchymal stem cells, MG63 and HEK293 transfection using chitosan-DNA nanoparticles. Biomaterials. 2003;24:1255-1264.

29. Jiang HL, Kim YK, Arote R, et al. Chitosan-graft-polyethylenimine as a gene carrier. J Control Release. 2007;117:273-280.

30. Strand SP, Lelu S, Reitan NK, De Lange Davies C, Artursson P, Varum KM. Molecular design of chitosan gene delivery systems with an optimized balance between polyplex stability and polyplex unpacking. Biomaterials. 2010;31:975-987.

31. Nagane K, Jo J, Tabata Y. Promoted adipogenesis of rat mesenchymal stem cells by transfection of small interfering RNA complexed with a cationized dextran. Tissue Eng, Part A. 2010;16:21-31.

32. Azzam T, Eliyahu H, Shapira L, Linial M, Barenholz Y, Domb AJ. Polysaccharide-oligoamine based conjugates for gene delivery. $J \mathrm{Med}$ Chem. 2002;45:1817-1824.

33. Hosseinkhani H, Azzam T, Tabata Y. Dextran-spermine polycation: an efficient non-viral vector for in vitro and in vivo gene transfection. Gene Ther. 2004;11:194-203.

34. Kanatani I, Ikai T, Okazaki A, et al. Efficient gene transfer by pullulanspermine occurs through both clathrin- and raft/caveolae-dependent mechanisms. J Control Release. 2006;116:75-82. 
35. Thakor DK, Teng YD, Tabata Y. Neuronal gene delivery by negatively charged pullulan-spermine/DNA anioplexes. Biomaterials. 2009;30: 1815-1826.

36. Katav T, Liu LS, Traitel T, Goldbart R, Wolfson M, Kost J. Modified pectin-based carrier for gene delivery: cellular barriers in gene delivery course. J Control Release. 2008;130:183-191.

37. Mizu M, Koumoto K, Anada T, et al. A polysaccharide carrier for immunostimulatory CpG DNAs to enhance cytokine secretion. $J \mathrm{Am}$ Chem Soc. 2004;126:8372-8373.

38. Eliyahu H, Siani S, Azzam T, Domb AJ, Barenholz Y. Relationships between chemical composition, physical properties and transfection efficiency of polysaccharide-spermine conjugates. Biomaterials. 2006;27:1646-1655.

39. Dong L, Xia S, Luo Y, et al. Targeting delivery oligonucleotide into macrophages by cationic polysaccharide from Bletilla striata successfully inhibited the expression of TNF-alpha. $J$ Control Release. 2009;134:214-220.

40. Carbonero ER, Gracher AHP, Smiderle FR. A $\beta$-glucan from the fruit bodies of edible mushrooms Pleurotus eryngii and Pleurotus ostreatoroseus. Carbohydr Polymer. 2006;66:252-257.

41. Wang $\mathrm{HX}, \mathrm{Ng} \mathrm{TB}$. Isolation of a new ribonuclease from fresh fruiting bodies of the straw mushroom. Biochem Biophys Res Commun.1999;264: 714-718.

42. Wang HX, Ng TB. Pleureryn, a novel protease from fresh fruiting bodies of the edible mushroom Pleurotus eryngii. Biochem Biophys Res Commun 2001;289:750-755.

43. Kim JH, Kim YS. Characterization of a metalloenzyme from a wild mushroom, Tricholoma saponaceum. Biosci Biotechnol Biochem. 2001;65:356-362.

44. Zhang M, Cui SW, Cheung PCK, Wang Q. Antitumor polysaccharides from mushrooms: a review on their isolation process, structural characteristics and antitumor activity. Trends Food Sci Tech. 2007;18: 4-19.

45. Kim GY, Lee JY, Lee JO, et al. Partial characterization and immunostimulatory effect of a novel polysaccharide-protein complex extracted from phellinus linteus. Biosci Biotechnol Biochem. 2006;70:1218-1226.

46. Muñoz C, Guillén F, Martínez AT, Martínez MJ. Laccase isoenzymes of Pleurotus eryngii: characterization, catalytic properties, and participation in activation of molecular oxygen and $\mathrm{Mn}^{2+}$ oxidation. Appl Environ Microbiol. 1997;63:2166-2174.

47. Pogni R, Baratto MC, Teutloff C, Giansanti S, Ruiz-Dueñas FJ, Choinowski T. Tryptophan neutral radical in the oxidized state of versatile peroxidase from Pleurotus eryngii: a combined multifrequency EPR and density functional theory study. $J$ Biol Chem. 2006;281:9517-9526.

48. Ruiz-Dueñas FJ, Morales M, Pérez-Boada M, et al. Manganese oxidation site in Pleurotus eryngii versatile peroxidase: a site-directed mutagenesis, kinetic, and crystallographic study. Biochemistry. 2007;46: $66-77$.

49. Kim SW, Kim HG, Lee BE, Hwang HH, Baek DH, Ko SY. Effects of mushroom, Pleurotus eryngii, extracts on bone metabolism. Clin Nutr. 2006;25166-25170.

50. Synytsya A, Mickova K, Synytsya A, et al. Glucans from fruit bodies of cultivated mushrooms Pleurotus ostreatus and Pleurotus eryngii: Structure and potential prebiotic activity. Carbohydr Polymer. 2009;76: $548-556$
51. Liu Z, Tabakman S, Welsher K, Dai H. Carbon nanotubes in biology and medicine: in vitro and in vivo detection, imaging and drug delivery. Nano Res. 2009;2:85-120.

52. Wang L, Zhao W, Tan W. Bioconjugated silica nanoparticles: development and applications. Nano Res. 2008;1:99-115.

53. Elisseeff J, McIntosh W, Fu K, Blunk BT, Langer R. Controlled release of IGF-I and TGF-beta1 in a photopolymerizing hydrogel for cartilage tissue engineering. J Orthop Res. 2001;19:1098-1104.

54. Guo CA, Liu XG, Huo JZ, Jiang C, Wen XJ, Chen ZR. Novel genemodified-tissue engineering of cartilage using stable transforming growth factor- $\beta 1$-transfected mesenchymal stem cells grown on chitosan scaffolds. J Biosci Bioeng. 2007;103:547-556.

55. Ciapetti G, Cenni E, Pratelli L, Pizzoferrato A. In vitro evaluation of cell/biomaterial interaction by MTT assay. Biomaterials. 1993;14: 359-364.

56. Institute for Laboratory Animal Research. Guide for the Care and Use of Laboratory Animals. Washington: National Academies Press; 1996. Available from http://oacu.od.nih.gov/regs/guide/guide.pdf. Accessed February 14, 2012.

57. Masuko T, Minami A, Iwasaki N, Majima T, Nishimura SI, Lee YC Carbohydrate analysis by a phenol-sulfuric acid method in microplate format. Anal Biochem. 2005;339:69-72.

58. Jun-ichiro J, Arimichi O, Kentaro N, Masaya Y, Yasuhiko T. Preparation of cationized polysaccharides as gene transfection carrier for bone marrow-derived mesenchymal stem cells. J Biomater Sci Polymer Ed. 2010;21:185-204

59. Alhadlaq A, Mao JJ. Mesenchymal stem cells: isolation and therapeutics. Stem Cells Dev. 2004;13:436-448.

60. Xu FJ, Zhang ZX, Ping Y, Li J, Kang ET, Neoh KG. Star-shaped cationic polymers by atom transfer radical polymerization from $\beta$-cyclodextrin cores for non-viral gene delivery. Biomacromolecules. 2009;10: 285-293.

61. Li Y, Zhu Y, Xia K, et al. Dendritic poly(L-lysine)-b-poly(L-lactide)b-dendritic poly(L-lysine) amphiphilic gene delivery vectors: roles of PLL dendritic generation and enhanced transgene efficacies via termini modification. Biomacromolecules. 2008;10:2284-2293.

62. Wang Y, Wang LS, Goh SH. Synthesis and characterization of cationic micelles self-assembled from a biodegradable copolymer for gene delivery. Biomacromolecules. 2007;8:1028-1037.

63. Ren Y, Jiang X, Pan D, Mao HQ. Charge density and molecular weight of polyphosphoramidate gene carrier are key parameters influencing its DNA compaction ability and transfection efficiency. Biomacromolecules. 2010;11:3432-3439.

64. Xu PS, Quick GK, Yeo Y. Gene delivery through the use of a hyaluronateassociated intracellularly degradable crosslinked polyethyleneimine. Biomaterials. 2009;30:5834-5843.

65. Guo T, Zhao J, Chang J, et al. Porous chitosan-gelatin scaffold containing plasmid DNA encoding transforming growth factor-betal for chondrocytes proliferation. Biomaterials. 2006;27:1095-1103.
International Journal of Nanomedicine

\section{Publish your work in this journal}

The International Journal of Nanomedicine is an international, peerreviewed journal focusing on the application of nanotechnology in diagnostics, therapeutics, and drug delivery systems throughou the biomedical field. This journal is indexed on PubMed Central, MedLine, CAS, SciSearch ${ }^{\circledR}$, Current Contents ${ }^{\circledR} /$ Clinical Medicine,

\section{Dovepress}

Journal Citation Reports/Science Edition, EMBase, Scopus and the Elsevier Bibliographic databases. The manuscript management system is completely online and includes a very quick and fair peer-review system, which is all easy to use. Visit http://www.dovepress.com/ testimonials.php to read real quotes from published authors. 